\title{
VII. Ergebnis: Die Gründe für die Barbarisierung der Isaurier
}

In dieser Arbeit war die Beziehung der Isaurier zum Römischen Reich während der ungefähr 900jährigen Periode ihrer historischen Präsenz zu untersuchen, insbesondere die genauen Gründe für die Barbarisierung der Isaurier und ihre letztlich gescheiterte Integration in das Machtgefüge des oströmischen Reiches. Dabei wurde gegen die Ansicht argumentiert, daß die Isaurier sich in einem dauernden Widerstand zum Römischen Reich befunden hätten. Vielmehr haben sie sich erst mit der Krise des 3. Jahrhunderts wieder erhoben und sind dann letztlich nicht mehr in das inzwischen durch die Goteneinfälle zermürbte Reich integriert worden. Den Goten mittlerweile in Plünderungszügen, Stellung von Truppenteilen im Heer und dem Streben nach Macht in Konstantinopel ähnlich, galten sie nun ebenso wie diese als Barbaren, woran selbst das Kaisertum eines Isauriers nichts mehr ändern konnte. Die Bezeichnung der Isaurier als Barbaren zieht sich dabei von den Autoren des 3. Jahrhunderts bis zu den Gegnern von Zenos Religionspolitik hin. Sie findet ihre Fortsetzung in der Bezeichnung für den des Ikonoklasmus verdächtigten Kaiser Leo III. als Begründer der ,isaurischen" Dynastie im 8. Jahrhundert: Der isaurische Ruf war längst sprichwörtlich schlecht geworden.

Nach einer Periode der römischen Eroberung des Taurusgebiets und dessen in den ersten beiden Jahrhunderten $\mathrm{n}$. Chr. friedlich vonstatten gegangener Romanisierung herrschte in der Hohen Kaiserzeit Ruhe in der Provinz. Erst die Einfälle des Perserheeres unter Schapur zerstörten das labile ökonomische Gleichgewicht und führten zusammen mit den gotischen Einfällen zu jenen ausgedehnten Raubzügen über den östlichen Mittelmeerraum um die Wende zum 5. Jahrhundert. Diese sind als Ausweichbewegung in Reaktion auf die seit der Schaffung der comitiva Isauriae gestiegene Militärpräsenz in Isaurien selbst zu interpretieren. Der Hauptgrund für das isaurische Banditentum ist weniger in einem nationalen Widerstandsgefühl als vielmehr in der schwachen ökonomischen Situation zu suchen, die durch die persischen und gotischen Einfälle sowie die überforderte Verwaltung hervorgerufen wurde.

Aufgrund der ständigen Bedrohung im 3. und 4. Jahrhundert durch isaurische Banditen wurde diese Volksgruppe von der übrigen Reichsbevölkerung abgelehnt und mit den übrigen plündernden gotischen Scharen gleichgesetzt. Vor allem in der Hauptstadt zeigten sich Ressentiments gegen die Isaurier nach deren Eindringen in die inneren Zirkel der Macht, was sich in ihrer Vertreibung aus dem öffentlichen Leben nach der Regierung Zenos unter Anastasius äußerte. So war zwar durch den Aufstieg 
isaurischer Machthaber die Möglichkeit einer vollständigen Integration der Isaurier ins Reichsgefüge gegeben, andererseits wurde diese durch die mangelnde Akzeptanz der konstantinopolitanischen Bevölkerung nach der zwölfjährigen isaurischen Herrschaft unter Zeno verhindert.

Sowohl Goten als auch Isaurier waren nun negativ im kollektiven Gedächtnis Konstantinopels verankert. Die Isaurier insgesamt hatten sich im Laufe des 3. und 4. Jahrhunderts bereits einen derart negativen Ruf erworben, daß sie zuweilen nicht nur als „gefährliche Nachbarn", sondern sogar als Feinde von innen angesehen wurden. Man verlieh ihnen das Etikett „Barbaren“, was eigentlich nur den von außen ins Reich eindringenden Goten und Hunnen zugedacht war.

Eine wesentliche Rolle bei dieser Entwicklung kam dabei den Goten zu. Mit der Eingliederung geschlossener isaurischer Truppenverbände durch Theodosius glichen diese auch darin ihren gotischen Mit-Barbaren. Diese Barbarisierung der isaurischen Militärs war nicht mehr rückgängig zu machen, zumal die Goten sich mittlerweile ganz selbstverständlich in selbstverfaßten Verbänden auf Reichsgebiet aufhalten und hohe Magistrate stellen konnten. Die Parallele in den Karrieren einzelner isaurischer Mächtiger zu den gotischen Führern, die sich am Kaiserhof um einflußreiche Stellungen und eine Versippung mit der kaiserlichen Familie bemühten, begann um die Mitte des 5. Jahrhunderts und setzte sich bis zum Tod des Isauriers Zeno auf dem Kaiserthron am 9. April 491 fort. Dabei wurden Isaurier sowohl von Theodosius II. als auch von Leo I. als Gegengewicht zu der gotisch-alanischen Gruppe um Aspar eingesetzt.

Die Isaurier standen ihrerseits in einem Spannungsverhältnis zwischen Selbstbehauptung und Integration. Mit Zenos Kaisertum, insbesondere seiner im Inneren und Äußeren auf religiöse Konsolidierung bedachten und auf Zurück- bzw. Herausdrängung der Goten abzielenden Politik, wurde ein Weg zur Integration der Isaurier ins Reich und der Konsolidierung des Reichs insgesamt beschritten. Jedoch angesichts des Drucks der Völkerwanderung wurden Fragen von Romanitas und ethnischer Identität in der Bevölkerung stärker beachtet; die selbst auf ihre Herkunft stolzen Isaurier blieben ausgegrenzt. Dies schlägt sich im Urteil der meisten Quellen über Zeno nieder.

Die verstärkte Betonung der Ethnizität ist nach unserer Ansicht geradezu ein konstitutives Merkmal der Spätantike im Gegensatz zur Hohen Kaiserzeit; in der Geschichte der Isaurier als barbarische Bürger im Reich tritt die Transformation des Imperium Romanum vom allumfassenden Vielvölkerstaat zu einem Gebilde, das die Grenzen der Integration erreicht hat, deutlich zutage. Als Soldaten in den justinianischen Kriegen spielten sie zwar eine wichtige Rolle, aber sie waren in dieser ohnehin kaum noch aus „Römern“ bestehenden Armee nur eines von vielen barbarischen Kontingenten, wenn auch das zahlreichste. 